\title{
Institutional Care of Children in Low- and Middle-Income Settings: Challenging the Conventional Wisdom of Oliver Twist
}

\author{
Paula Braitstein ${ }^{a}$
}

\begin{abstract}
Whether institutions or extended families are better suited to care for orphans depends on the specific circumstances. Reported rates of traumatic experiences among orphans and vulnerable children are high in both institutions and extended families; improving the quality of care for such children should be the paramount priority in all settings.
\end{abstract}

See related article by Gray.

A cting in the best interest of the child is the fundamental principle that is supposed to guide local, national, and international policy, programming, research, and care for children. Most people would agree, yet there is a raging debate among scientists about how, what, where, and when to measure and interpret "best interests." The stakes are high as there are millions of children lacking one or both parents (orphans) and millions more whose parents are alive but due to poverty or other circumstances such as substance abuse can't, or at least don't, provide them with an optimal care environment-or sometimes even one that meets their basic needs. Consequently, millions of children, especially in low- and middle-income countries, turn to the streets in an effort to take care of themselves.

On one side is a large body of evidence, mostly historical and from Eastern Europe and North America, about the negative physical and mental health outcomes of children in institutions. ${ }^{1}$ In essence, the evidence clearly demonstrates that socially and emotionally deprived environments are bad for children and that institutions caring for infants, particularly in Eastern Europe and North America, have embodied neglectful environments. As a result of this evidence, there are global demands for universal deinstitutionalization.

Yet the paper by Gray and colleagues published in Global Health: Science and Practice challenges stakeholders to perhaps rethink these sweeping conclusions. ${ }^{2}$ Their data, from a multicenter cohort of school-aged children in 5 low-income countries, indicate that children in family-

a University of Toronto, Dalla Lana School of Public Health, Toronto, ON, Canada.

Correspondence to Paula Braitstein (pbraitstein@gmail.com). based settings actually had a higher risk of physical or sexual abuse compared with those living in institutions, and children in family-based environments were as likely as those in institutions to report experiencing at least one potentially traumatic event. Although limited by the selfreported nature of the data, these findings are supported by a rapidly growing body of evidence to suggest that, at least in low- and middle-income countries, institutional environments may sometimes be better equipped and prepared to care for children in need than many extended families and other family-based configurations of care. ${ }^{3-8}$

It is a counter-intuitive idea. Charles Dickens brought us Oliver Twist and with it enduring social and cultural icons of institutions being inherently harmful for children. Residential schools in Australia, Canada, and the United States have strongly reinforced this idea by leaving aboriginal communities and First Nations struggling to cope with lasting multigenerational trauma resulting from the schools. When Nicolae Ceauşescu was eventually deposed and Romania exposed to the outside world, horrifying images of children in institutions imprinted themselves onto our collective mind with the undisputed message that institutions are bad for children.

Truly, it is doubtful that any child would wish a priori to grow up in an institution, and there is no denying the potential for neglect and severe abuse to occur in institutions in the absence of appropriate resources, regulation, and oversight. The question is whether institutional environments themselves are necessarily bad environments for children. The vast majority of data about children in institutional environments has come from high- and very high-income settings, and often without comparison groups. This 
literature may be subject to publication bias, because the more shockingly negative findings are, the more likely they are to get published. The horrific images and data from children in Romania stay with us and lead us to draw the strong conclusions to which Gray and her coauthors allude: institutions should all be closed. But steadily, piece by piece, there is another picture emerging that just maybe, given the widespread poverty, rapid urbanization, ${ }^{9}$ and high dependency ratios that characterize many extended families in sub-Saharan Africa ${ }^{10}$ and Asia, institutions are not so bad for children in those places, particularly when compared with their compatriots living with extended family. At least, they appear to be no worse.

Regardless of which side of the deinstitutionalization debate one takes, what also especially deserves attention from this paper is the fact that over $90 \%$ of participating children in both environments reported experiencing at least one potentially traumatic event other than the death of a parent. ${ }^{2}$ Over $50 \%$ of both groups reported at least one episode of physical or sexual abuse by age 13, and physical or sexual abuse was the leading cause of incident trauma in the cohort. One might surmise these to be unsurprising findings for children living in institutional environments given the background circumstances that presumably led to them becoming institutionalized. However, the fact that so many children in both care environments experienced potentially traumatic events-and physical and/or sexual abuse in particular-is alarming. These rates are unacceptably high, but why could they be higher in families than in institutions?

There are several theories, all of which need testing. One is that at least in some settings, the majority of institutions are funded through adequately resourced religious organizations and so are better able to respond to the material needs of children. ${ }^{5}$ There is evidence that orphaned girls, especially, exchange sex for material goods in order to survive; if this need is taken away their risk of sexual abuse will be lessened. ${ }^{11,12}$ It may also be possible that many of the staff, or at least founders, of institutions in low-income settings are working in, or have set up, the institution explicitly because they want to take care of children. In contrast, there is a broad literature indicating many extended families are forced into caring for orphans because of family or cultural expectations. They may already be struggling financially and view the orphaned child as an added burden. There is a body of evidence that indicates that orphans are often systematically discriminated against within the household in which they are living. ${ }^{13,14}$ In essence, extended families in many areas are stretched to the limit financially and perhaps emotionally. Families are not generally supported to care for orphaned children although thanks to support from governmental and nongovernment organizations, more and more families are receiving small cash subsidies. The subsidies do seem to help significantly. ${ }^{15}$

The evidence is mounting that at least in some places, institutional environments actually create family-like environments. ${ }^{5}$ Moreover, there is plenty of evidence including the paper by Gray et al. that illustrates a high burden of abuse and neglect among orphans living with family. ${ }^{16}$ Indeed the one potentially traumatic event that was higher for institutionalized children in Gray et al.'s study was being forced to leave the home or care setting - the authors speculate that this is likely due to the closing of institutions in which they were living.

Thus, the answer to the question posed earlier appears to be: "No, there is nothing necessary about living in an institution that seems to be inherently bad for a child." As more and higher quality data from low- and middle-income countries emerge, the idea that it is the quality and characteristics of the care within an environment, rather than the type of environment itself, that most likely impacts a child's health and wellbeing, is likely to grow.

In many ways, the debate on institutionalization is asking the wrong question. The questions we should be asking ourselves are how do we prevent traumatic events among vulnerable children across the board-regardless of the care environment? How do we create a world in which most children can grow into their teens without experiencing a potentially traumatic event? How do we support those who have experienced a traumatic event? How do we support families to take better care of the children in their charge in the context of poverty, culture, urbanization, and the rapidly changing world we are all trying to adapt to? What is the role of institutions for children in need of a safety net? How should they be structured to respond adequately to the physical and emotional needs of infants, toddlers, young children, and adolescents? What are the optimal care characteristics within any environment that maximize resiliency and break the cycles of poverty, exploitation, and abuse among young people?

\section{A growing body of evidence suggests institutions may sometimes be better equipped to care for children in need than extended families, especially in low- and middle-income countries.}


These are the next questions that need to be asked-and answered-by scientists engaged in the debate about what is in the best interests of vulnerable children globally. One can only hope that all stakeholders in the discussion can keep open minds, let the evidence evolve, and develop best practices that are truly in the best interests of children in all regions of the world-ones that do not hang on the image of poor little Oliver Twist.

Acknowledgments: This work was supported in part by the Eunice Kennedy Shriver National Institute Of Child Health \& Human Development [R01HD060478]. The content is solely the responsibility of the author and does not necessarily represent the official views of the Eunice Kennedy Shriver National Institute of Child Health \& Human Development or the National Institutes of Health.

Competing Interests: Dr. Braitstein reports grants from Eunice Kennedy Shriver National Institute of Child Health \& Human Development during preparation of this paper for similar research.

\section{REFERENCES}

1. Berens $A E$, Nelson CA. The science of early adversity: is there a role for large institutions in the care of vulnerable children? Lancet. 2015;386(9991):388-398. CrossRef. Medline

2. Gray CL, Pence BW, Ostermann J, Whetten RA, O'Donnell K, Thielman NM, Whetten K. Prevalence and incidence of traumatic experiences among orphans in institutional and family-based settings in 5 low- and middle-income countries: a longitudinal study. Glob Health Sci Pract. 2015;3(3):395-404. CrossRef.

3. Atwoli L, Ayuku D, Koech J, Hogan JRCV, Braitstein P. Impact of domestic care environment on trauma and posttraumatic stress among orphans in western Kenya. PLoS One. 2014;9(3): e89937. CrossRef. Medline

4. Braitstein P, Ayaya S, Nyandiko WM, Kamanda A, Koech J, Gisore $P$, et al. Nutritional status of orphaned and separated children and adolescents living in community and institutional environments in uasin gishu county, kenya. PLoS One. 2013;8(7): e70054. CrossRef. Medline

5. Embleton L, Ayuku D, Kamanda A, Atwoli L, Ayaya S, Vreeman R, et al. Models of care for orphaned and separated children and upholding children's rights: cross-sectional evidence from western Kenya. BMC Int Health Hum Rights. 2014;14(1):9. CrossRef. Medline

6. Whetten K, Ostermann J, Pence BW, Whetten RA, Messer LC, Ariely S, et al. Positive Outcomes for Orphans (POFO) Research Team. Three-year change in the wellbeing of orphaned and separated children in institutional and family-based care settings in five low- and middle-income countries. PLoS One. 2014;9(8): e104872. CrossRef. Medline

7. Whetten K, Ostermann J, Whetten RA, Pence BW, O'Donnell K, Messer LC, et al. Positive Outcomes for Orphans (POFO) Research Team. A comparison of the wellbeing of orphans and abandoned children ages 6-12 in institutional and communitybased care settings in 5 less wealthy nations. PLoS One. 2009; 4(12):e8169. CrossRef. Medline

8. Lin X, Fang X, Zhao J, Lan J, Li X. Physical and psychological health among children affected by HIV/AIDS: difference in groups and caring arrangements. Chin J Clin Psychol. 2009; 17(6):733-735.

9. United Nations Children's Fund (UNICEF). The state of the world's children 2012: children in an urban world. New York: UNICEF; 2012. Available from: http://www.unicef.org/sowc/files/ SOWC_2012-Main_Report_EN_21Dec2011.pdf

10. Miller CM, Gruskin S, Subramanian SV, Rajaraman D, Heymann SJ. Orphan care in Botswana's working households: growing responsibilities in the absence of adequate support. Am J Public Health. 2006;96(8):1429-1435. CrossRef. Medline

11. Hallfors D, Cho H, Rusakaniko S, Iritani B, Mapfumo J, Halpern C. Supporting adolescent orphan girls to stay in school as HIV risk prevention: evidence from a randomized controlled trial in Zimbabwe. Am J Public Health. 2011;101(6):1082-1088. CrossRef. Medline

12. Miller T, Hallfors D, Cho H, Luseno W, Waehrer G. Costeffectiveness of school support for orphan girls to prevent HIV infection in Zimbabwe. Prev Sci. 2013;14(5):503-512. CrossRef. Medline

13. Govender K, Reardon C, Quinlan T, George G. Children's psychosocial wellbeing in the context of HIV/AIDS and poverty: a comparative investigation of orphaned and non-orphaned children living in South Africa. BMC Public Health. 2014; 14(1):615. CrossRef. Medline

14. Monasch R, Boerma JT. Orphanhood and childcare patterns in sub-Saharan Africa: an analysis of national surveys from 40 countries. AIDS. 2004;18 (Suppl 2):S55-S65. CrossRef. Medline

15. Ayuku D, Embleton L, Koech J, Atwoli L, Hu L, Ayaya S, et al. The government of Kenya cash transfer for orphaned and vulnerable children: cross-sectional comparison of household and individual characteristics of those with and without. BMC Int Health Hum Rights. 2014;14(1):25. CrossRef. Medline

16. Morantz G, Cole D, Vreeman RC, Ayaya S, Ayuku D, Braitstein P. Child abuse and neglect among orphaned children and youth living in extended families in sub-Saharan Africa: what have we learned from qualitative inquiry? Vulnerable Child Youth Stud. 2013;8(4):338-352. CrossRef. Medline

Cite this article as: Braitstein $\mathrm{P}$. Institutional care of children in low- and middle-income settings: challenging the conventional wisdom of Oliver Twist. Glob Health Sci Pract. 2015;3(3):330-332. http://dx.doi.org/10.9745/GHSP-D-15-00228.

(c) Braitstein. This is an open-access article distributed under the terms of the Creative Commons Attribution License, which permits unrestricted use, distribution, and reproduction in any medium, provided the original author and source are properly cited. To view a copy of the license, visit http://creativecommons.org/licenses/by/3.0/. When linking to this article, please use the following permanent link: http://dx.doi.org/10.9745/GHSP-D-15-00228. 